\title{
YOGA ATASI NYERI SAAT MENSTRUASI PADA REMAJA PUTRI
}

\author{
Julaecha \\ Prodi D III Kebidanan STIKBA Jambi \\ Email.echa_mamee@yahoo.com
}

\begin{abstract}
Menstruation is part of a regular process that prepares a woman's body every month for pregnancy, which is controlled by the interaction of hormones released by the hypothalamus. In general, women experience physical discomfort for several days before and during the first day of menstruation in the form of pain or dysmenorrhea. Dysminorrhea is pain that arises during menstruation which can interfere with daily activities. The prevalence of dysminorrhea in Indonesia around 50\% occurs in young women. As a result of menstrual pain, among others: about $20 \%$ of adolescents can not go to school because of pain during menstruation, so that academic achievement decreases. There are several pain management to overcome dysminore one of which is with yoga. The purpose of community service is to provide information to adolescents about how to cope with pain during menstruation without painkillers with yoga movements the balasana movemens. The materials used in this activity were leaflets, infocations, laptops, questionnaires and stationery, while this activity was carried out on April 13-15 at MTS Darussalam Al-Hafiz Jambi City. The results of this community service were female students knowing how to overcome pain during menstruation by doing one of the yoga poses of child pose to reduce pain during menstruation.
\end{abstract}

Keywords: disminore, young women, yoga

\begin{abstract}
ABSTRAK
Menstruasi merupakan bagian dari proses regular yang mempersiapkan tubuh wanita setiap bulannya untuk kehamilan, yang dikendalikan oleh interaksi hormon yang dikeluarkan oleh hipotalamus. Pada umumnya wanita mengalami ketidanyamanan fisik selama beberapa hari sebelum dan pada saat hari pertama menstruasi berupa nyeri atau dismenore. Disminore adalah nyeri yang timbul saat menstruasi yang dapat menganggu aktifitas sehari-hari. Prevalensi disminore di Indonesia sekitar 50\% terjadi pada remaja putri. Akibat dari nyeri saat menstruasi antara lain: sekitar 20\% remaja tidak dapat masuk sekolah karena nyeri saat menstruasi, sehingga prestasi akademik menurun.Ada beberapa manajemen nyeri untuk mengatasi disminore salah satunya adalah dengan yoga. Tujuan pengabdian masyarakat ini untuk memberikan informasi kepada remaja tentang cara mengatasi nyeri saat menstruasi tanpa obat penghilang rasa sakit dengan gerakan yoga yaitu gerakan balasana. Bahan yang digunakan pada kegiatan ini adalah leaflet, infokus, leptop, kuesioner dan alat tulis, adapun kegiatan ini dilakukan pada pada tanggal 13-15 April di MTS Darussalam Al-Hafiz Kota Jambi, Hasil dari pengabdian masyarakat ini adalah siswi putri mengetahui memahami cara mengatasi nyeri saat menstruasi dengan melakukan salah satu gerakan yoga child pose untuk mengurangi nyeri saat menstruasi.
\end{abstract}

Kata Kunci : disminore, remaja putri, yoga 


\section{PENDAHULUAN}

Masa remaja merupakan periode yang ditandai dengan pertumbuhan dan perkembangan yang cepat dari fisik, emosi, kognitif dan sosial, Perubahan baik secara biologis, kognitif maupun psikologis, sebagai tanda kematangan reproduksi perempuan yaitu datangnya menstruasi. Menstruasi merupakan bagian dari proses regular yang mempersiapkan tubuh wanita setiap bulannya untuk kehamilan, yang dikendalikan oleh interaksi hormon yang dikeluarkan oleh hipotalamus. Pada umumnya wanita mengalami ketidanyamanan fisik selama beberapa hari sebelum dan pada saat hari pertama menstruasi berupa nyeri atau dismenore.(Proverawati 2009)

Mentruasi adalah pengeluaran darah dan sel-sel tubuh dari vagina yang berasal dari dinding rahim perempuan secara periodik, menstruasi juga dapat diartikan sebagai siklus alami yang terjadi secara reguler untuk mempersiapkan tubuh perempuan setiap bulannya, rata-rata lama mentruasi adalah 3-8 hari dengan siklus rata-rata 28 hari pada setiap bulannya, dan batas maksimal masa haid adalah 15 hari, selama darah yang keluar belum melewati batas tersebut, maka darah yang keluar adalah darah haid. (Dito, Anrogo 2011)

Dismenore adalah keadaan nyeri di bagian abdomen, kram, dan sakit punggung serta dapat mengganggu aktivitas seharihari. Dismenore dibedakan menjadi dua yaitu dismenore primer dan dismenore sekunder. Dismenore primer terjadi karena produksi prostaglandin yang lebih besar sehingga menyebabkan kontraksi uterus, iskemia uterus, dan nyeri pelvis. Dismenore sekunder terjadi akibat berbagai kondisi patologis seperti endometriosis, salfingitis, dan kelainan duktus. (Kusmiran, 2011)

Prevalensi dismenore didunia sangat besar yaitu rata-rata lebih dari $50 \%$ perempuan di setiap dunia mengalami nyeri saat menstruasi. Prevalensi disminore di
Indonesia sebesar $64,25 \%$ yang terdiri dari $54,88 \%$ disminore primer dan 9,36 disminore sekunder. Kejadian disminore merupakan kejadian alamiah yang terjadi setiap bulan pada wanita. Walaupun pada umumnya tidak berbahaya namun dapat menganggu aktifitas sehari-hari. (Meliana. 2016)

Salah satu dampak yang terjadi pada saat nyeri menstruasi adalah ketidakhadiran baik ditempat kerja maupun di sekolah yang dapat mengakibatkan prestasi turun, Hal inilah yang memerlukan penanganan yang cukup serius bagi perempuan yang mengalami nyeri saat menstruasi sehingga tidak menagnggu aktifitas sehari-hari. Didukung oleh penelitianYulinda mengatakan bahwa beberapa remaja putri sering tidak mengikuti perkuliahan dan tidak dapat hadir saat kuliah karena sakit saat menstruasi yang berakibat pada berkurangnya presentasi kehadiran dan berdampak pada penguasaan topik mata kuliah. (Yulinda 2017)

Upaya penanganan disminore dapat dilakukan dengan 2 cara yaitu farmakologi dengan analgesik dan hormonal sedangkan secara dan non farmakologi dapat dilakukan kompres hangat, massase, latihan fisik, tidur, hipnoterapi, dan yoga. Yoga merupakan tehnik relaksasi yang mengajarkan seperangkat tehnik seperti pernafasan, meditasi dan posisi tubuh untuk meningkatkan kekuatan dan keseimbangan. Tehnik relaksasi dalam yoga dapat merangsang tubuh untuk melepaskan opioid endogen yaitu endorphin dan enkefalin merupakan hormon yang berfungsi sebagai obat penenang alami/senyawa yang berfungsi untuk menghambat nyeri. (Asmadi 2008).

Berdasarkan uraian latar belakang diatas, penulis tertarik untuk melakukan pengabdian kepada masyarakat tentang terapi non farmakologi atasi nyeri saat 
menstruasi dengan gerakan yoga di MTS Darussalam Al-Hafiz Kota Jambi

\section{TARGET DAN LUARAN}

\section{Target}

Target yang diharapkan pada pengadian masyarakat ini antara lain:

1) Peningkatan pengetahuan remaja putri tentang nyeri saat menstruasi dan cara mengatasi nyeri secara non farmakologi atau alamia dengan memberikan penyuluhan dan demonstrasi salah satu gerakan yoga yaitu gerakan balasana yang mudah dilakukan dan tidak memerlukan biaya dan dapat dilakukan swaktu- waktu

2) Pihak sekolah bekerjasama dengan sektor kesehatan untk melakukan pembentukan teman sebaya, dan memberikan pendidikan kesehatan reproduski secara kontinyu.

\section{Luaran}

Luaran dari pengabdian masyarakat tentang gerakan yoga atasi nyeri saat mentruasi dapat diintegrasikan kedalam mata kuliah kesehatan reproduksi karena mudah dilakukan dan tidak memerlukan alat. Yoga hanya melibatkan sistem otot dan respirasi sehingga mudah dilakukan kapan saja atau sewaktu-waktu dan berdasarkan beberapa penelitian terbukti menurunkan nyeri saat menstruasi

\section{METODE PELAKSANAAN}

Pelaksanaan kegiatan pengabdian kepada masyarakat tentang terapi non farmakologi atasi nyeri saat mensruasi dengan menjelaskan tentang disminore dengan salah satu gerakan yoga yaitu posisi balasana ini dilakukan di MTS Darussalam Al-Hafiz Kota Jambi, pada tanggal 13-15 April 2019. Adapun metode dan bahan yang digunakan dalam pengabdian kepada masyarakat ini adalah leaflet, infokus, leptop, kuesioner dan alat tulis. Pelaksanaan kegiatan pengabdian kepada masyarakat ini melalui beberapa tahapan sebagai berikut:
1. Melakukan survei lokasi pengabdian kepada masyarakat

2. Menjelaskan maksud dan tujuan dilakukan pengabdian kepada masyarakat untuk memberikan penyuluhan tentang disminore dan cara penanganan nyeri haid secara non farmakologi

3. Mendata jumlah peserta yang hadir dan memberika kuesioner tentang disminore dan cara penanaganan nyeri

4. Melakukan penyuluhan tentang disminore dan cara penanganan disminore secara non farmakologi diantaranya adalah demonstrasi gerakan yoga yaitu gerakan balasana untuk penangana nyeri saat menstruasi

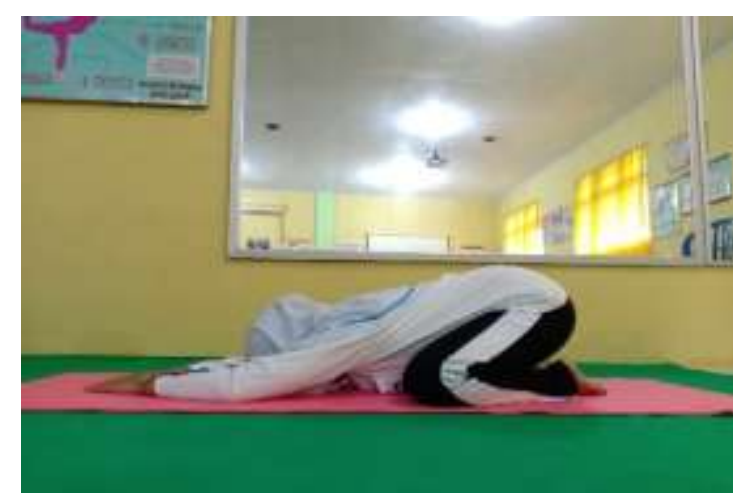

Gambar 1. Posisi balasana

5. Gerakan Balasana:

Berdiri diatas lutut. Satukan kedua jempol kaki dan biarkan jari-jari kaki rileks ke belakang. Buka lutut ke samping selebar sisi tubuh kemudian duduklah diatas tumit kaki, pelan-pelan turunkan perut, dada dan dahi diatas matras, luruskan tangan ke depan dan rilekskan kedua tangan. Tujuan gerakan ini adalah merilekskan tubuh, erutama bagian perut, panggul dan rahim, menyeimbangkan sistem hormon, dan meringankan nyeri saat menstruasi.

6. Membuka sesi tanya jawab

7. Mengevaluasi pemahaman remaja putri tentang terapi non farmakologi atasi nyeri saat menstruasi dan 
mendemonstrasikan ulang gerakan yoga yaitu posisi balasana untuk mengurangi nyeri haid

\section{HASIL DAN PEMBAHASAAN}

Hasil kegiatan pengabdian kepada terhadap remaja putri di MTS Darussalam Al-Hafiz Kota Jambi antara lain sebagai berikut:

Tabel 1. Hasil Kegiatan Pengabdian Kepada Masyarakat

Karakteristik Frekuensi Presentase

\section{Menstruasi}

$\begin{array}{lrr}\text { Sudah } & 54 & 85,7 \\ \text { Belum } & 9 & 14,2\end{array}$

2. Usia

\section{Menarche}

10 tahun 2

11 tahun 13

12 tahun

25

14

24,1

13 tahun

$$
46,3
$$$$
25,9
$$

\section{Lama}

\section{Menstruasi}

$\begin{array}{lll}\text { 4-7 hari } & 41 & 75,9 \\ \text { >7 hari } & 13 & 24,1\end{array}$

Berdasarkan tabel diatas menunjukkan dari 63 remaja putri di MTS Darussalam Al-Hafidz Kota Jambi 54 orang telah mendapatkan menstruasi dan 9 orang belum mendapatkan menstruasi. Dan mayoritas remaja putri mendapatkan menstruasi pertama kali pada umur 12 tahun sebanyak 25 orang. Mayoritas remaja putri mendapatkan menstruasi selama 4-7 hari sebanyak 41 orang.

Disminore dapat emnagnggu aktivitas perempuan , bahkan seringkali mengharuskan penderita beristirahat dan emninggalkan perkuliahan selama berjamjam akibat nyeri. Nyeri pada saat menstruasi terjadi karena endometrium dalam fase sekresi memproduksi prostaglandin berlebihan yang menyebabkan hipertonus dan vasokontriksi pada miometrium sehingga mengakibatkan iskemia, disintegrasi endometrium , perdarahan dan nyeri. (Wiknjosastro 2008)

Nyeri saat menstruasi atau disminore jika tidak segera diatasi maka akan memengaruhi fungsi mental dan fisik individu, oleh karena itu perlu penanganan untuk mengatasi nyeri baik secara farmakologi maupun non farmakologi. Salah satu terapi farmakologi yaitu dengan pemberian obat analgesik dengan cara memblok prostaglandin yang meneyebabkan nyeri,Terapi non farmakologi juga diperlukan untuk mengurangi nyeri saat menstruasi salah satunya dengan menggunakan tehnik relaksasi, olahraga dan yoga. (Asmadi 2008)

Yoga merupakan tehnik mengajarkan tehnik relaksasi, pernafasan dan posisi tubuh untuk meningkatkan kekuatan, keseimbangan dan mengurangi nyeri. Dengan cara merileksasikan otot-otot skelet yang mengalami spasme yang disebabkan oleh peningkatan prostaglandin sehingga terjadi vasodilatasu pembuluh darah dan akan meningkatkan aliran darah ke daerah yang mengalami spasme. salah satu gerakan yoga yaitu gerakan balasana, frekuensi latihan yoga dapat dilakukan 10-15 menit atau sebanyak 2 kali dalam 10 kali hitungan. Sambil mengatur nafas dalam. ( Senior 2008)

Hasil penelitian yang dilakukan oleh Melda Friska (2015) tentang efektifitas yoga terhadap nyeri saat disminore pada remaja di Riau menunjukkan bahwa yoga efektif dalam enurunkan nyeri saat menstruasi. Didukung oleh penelitian yang dilakukan oleh Kartika (2012) tentang penurunan tingkat disminore pada mahasiswa Fakultas Ilmu Keperawatan UNPAD menyimpulkan bahwa dengan melakukan yoga responden mengalami penurunan intensitas nyeri. 
Yoga menjadi salah satu alternatif pilihan olahraga yang memiliki banyak manfaat sehingga semakin diminati banyak orang. Salah satu manfaat utama dan paling nyata dari yoga adalah meningkatnya fleksibilitas. Asana salah satu unsur yoga yang berkaitan dengan postur atau gerakan, dapat melenturkan otot dan jaringan pengikat disekitar tulang sendi. Proses ini melepaskan asam laktat yang biasanya menyebabkan kekakuan, ketegangan, nyeri serta kelelahan. Sehingga latihan yoga secara teratur dapat mencegah munculnya berbagai keluhan di area tersebut. (Woodyard 2011).
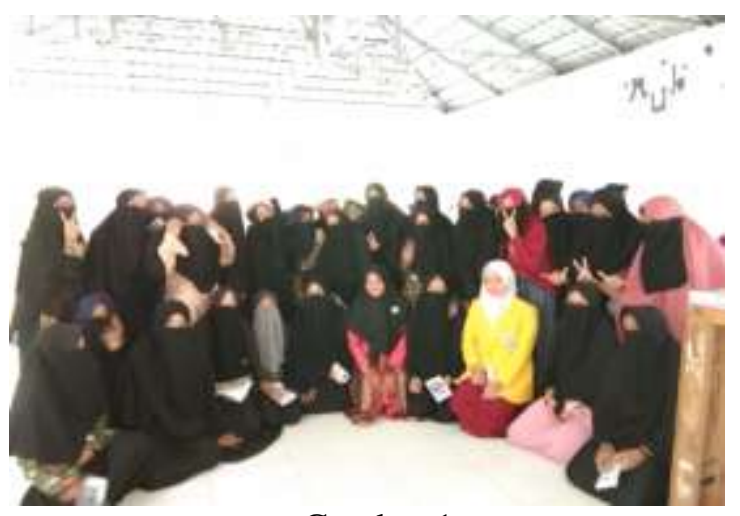

Gambar 1

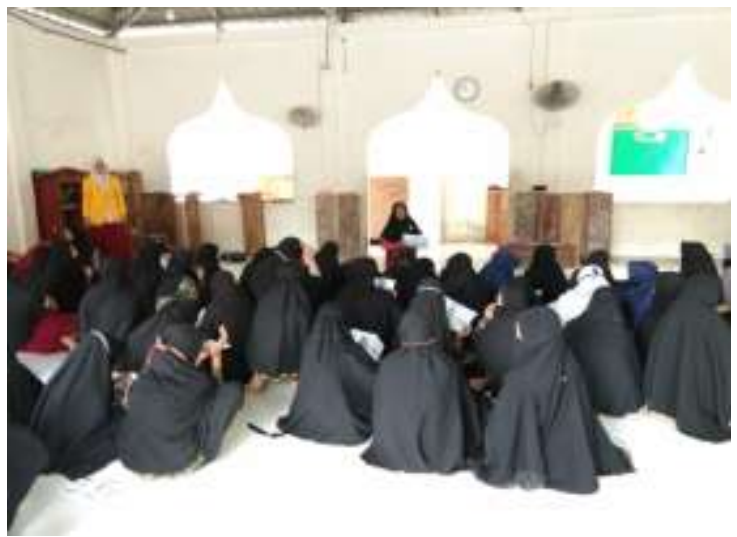

Gambar 2

Gambar 1dan 2. Foto Kegiatan Pengabdian Kepada Masyarakat.

\section{KESIMPULAN DAN SARAN}

\section{Kesimpulan}

Gerakan yoga dapat menjadi salah satu alternatif tindakan manajemen nyeri secara non farmakologi yang dapat dijadikan sebagai metode untuk menurunkan intensitas nyeri saat menstruasi, mudah dilakukan dan dapat dilakukan kapan saja, menstruasi dan cara penanganan nyeri saat menstruasi secara non farmakologi salah satunya gerakan yoga dapat diintegrasikan kedalam mata pelajaran kesehatan reproduski.

\section{Saran}

Pengabdian kepada masyarakat ini diharapakan dapat menambah wawasan bagi remaja putri dalam memahami disminore dan dapat menggunakan yoga untuk menangani nyeri saat menstruasi

\section{UCAPAN TERIMA KASIH}

Terima kasih kepada Bapak Ketua Sekolah Tinggi Ilmu Kesehatan Baiturrahim Jambi yag telah memberikan dana dan Bapak kepala sekolah MTS Darussalam Al-Hafiz yang telah memberikan izin memfasilitasi kegiatan pengabdian masyarakat ini

\section{DAFTAR PUSTAKA}

Asmadi 2008 Tehnik Prosedural Keperawatan:Konsep dan Aplikasi Kebutuhan DAsar Klien. Jakarta Salemba Medika

Dito, Anrogo. 2011. Cara Jitu Mengatasi Nyeri Haid, Yogyakarta

Kusmiran, 2011 Kesehatan reproduksi remaja dan wanita Salemba Medika, Jakarta

Kartika Siahaan, Ermiati, Ida Maryati. 2012 Penuruanan tingkat disminore pada mahasiswi Fakultas Ilmu Keperwatan UNPAD dengan menggunakan Yoga.

Meliana Fatmawati, Emmy R, Bagoes W. 2016 Perilaku Remaja Putri dalam Mengatasi dismenore Studi Kasus 
pada siswi SMK Negeri 11 Semarang, Jurnal Kesehatan Masyarakat eJournal volume , Nomor 3, Juli 2016

Melda Friska Manurung, Sri Utami, Siti Rahmalia HD. 2015 Efektifitas Yoga Terhadap Nyeri Disminore pada Remaja. JOM Vo. 2 No. 2 Oktober 2015

Proverawati, A Maisaroh. 2009 Menarche Menstruasi Pertama Penuh Makna. Yogyakarta. Nuha Medik.

Wong D, dkk 2009 Buku Ajar Keperawatan Pediatrik Volume I, EGC Jakarta

Wibowo 2008 Disminore Tinjauan Terapi pada Disminore, Jakarta, Bagian Ilmu Kebidanan dan Penyakit Kandungan. Fakultas Kedokteran Rumah Sakit UNIKA Atma Jaya)

Yulinda, Dewi Purwaningsih, Cherly M 2017 Latihan Yoga Dapat menurunkan tingkat kecemasan pada siklus menstruasi remaja putri. Indonesian Journal of Nursing and Midwifery ISSN 235-7642 